\title{
Rhythm in Architecture: an Aesthetic Appeal
}

\author{
Rena Thapa \\ Lalit Kala Campus, Bhotahity, Tribhuvan University, Kathmandu, Nepal \\ Corresponding author: renabha75@gmail.com
}

Received: Nov 12, 2017 Revised: Dec 15, $2017 \quad$ Accepted: Dec 20, 2017

\begin{abstract}
It is a discourse that exhibits the presence of rhythm in visual art, especially the architecture that holds strong aesthetic appeal. In this paper, the introduction part focuses on how rhythm generally reinforces aesthetic experiences in human sensory. Rhythm in architecture means recurrence of elements such as lines, shapes, forms or colors resulting on organized movement in space and time. I have taken the best analogy and examples of rhythm present in nature which has been formulated by scientist as Fibonacci number. I have tried to show architectures incorporating rhythm in different epoch of human civilization around the globe that have been popular and remarkable till the date. These architectural monuments have become aesthetic timeless entity, such as pyramids in Egypt, Parthenon in Greece, gothic architecture of medieval Europe, Tajmahal in India, Hindu temples and Buddha stupas in Nepal etc. Similarly modern architecture has been in equal focus in this article despite its unique and functional structures. The paper has been concluded with the strong statement that however the sense of beauty is shaped by cultural experience, rhythm is frequently desired with architectural compositions. These qualities are often universally admired and celebrated irrespective of time and place.
\end{abstract}

Key words: Aesthetic, harmony, rhythm, equilibrium, phyllotaxis

\section{Introduction}

Structure in the work of art carries a wide variety of messages. Artist may use different elements in the structure of visual art, such as shape, forms, space, color, texture etc to induce rhythm. This is equally applicable in verbal art by using literary devices. Human beings enjoy rhythm in various realms like in music, art, architecture and even in nature. Rhythm is one of the architectural means that creates specific architectural atmosphere. When certain elements are repeated in the work of art, whether it is in music, poetry, painting or architecture it creates a sense of movement, a sense of rhythm in the audience. Rhythm is so important in human nature that there is a link between rhythm and nature, rhythm and evolution, and rhythm and emotion. Architects tend to include a unifying motif on the inside and outside building to enhance aesthetic appeal. Aesthetics as the philosophy of art treats the nature of works of art that engenders a specific aesthetic experience in audience. It refers to the principles that govern the nature and the principle of beauty, artistic taste especially of visual art. The essentialist theory of aesthetics give priority to beauty, that is understood through intuition believing human feelings such as pleasure, rage, grief, suffering and joy to be the base of aesthetic experience. Richard Eldridge states that aesthetics deals with the natures and conditions 
of occurrences of various human experiences; the experiences of "the beautiful, the garish, the cute" [4].

The most prominent sensory system in perception research, and may be the most dominant modality in our experience of the world, is the visual system. The main function of our visual system is to allow us to navigate through the world without bumping into objects or falling from cliffs all the time. Vision therefore allows us to detect obstacles, see passages, estimate distances; to see what actions the world affords. Likewise vision also plays a prominent role in the identification of things, to signal us whether something is indeed one thing (partly hidden by something else), a possible resource or refuge, or potentially dangerous. The repeated design provides a consistent visual experience and that experience conforms the aesthetic one. However the repetition may occur with specific regular interval like the heart beat or with random spacing or even with frequent pattern all over like falling of snow. Repetition in any forms of rhythm whether in music or in architecture is an extremely simple principle of composition which tends to give a sense of coherence. Friedrich Nietzsche enforces rhythm as " a compulsion" that engenders "an unconquerable urge to yield and join in; not only our feet follow the beat the soul does, too- probably, one surmised, the soul of gods as well! Thus one tried to compel the gods by using rhythm and exercise control over them" [7].

\section{Rhythm in Nature}

The natural world in which we live, and of which we humans constitute a part, works on the basis of cycle. Physics formulates that every natural process tends to run down and stop because the energy back of it becomes exhausted in overcoming resistance, and changes to some other form. Whatever may seem to be a continuing process is really a moving equilibrium which continues by rhythm or cycle; one force dominates for a time, only to yield the dominance sooner or later to some other force. Every process goes by ebb and flow like the tides of the sea. A stream has a winding course because the current impinges against the banks, first on one side, and then on the other. Day alternates with night, winter alternates with summer. There are also longer cycles: for a series of years there is abundant rainfall, then for some years succeeding these the rainfall is scanty; sun-spots have their cycles, and electrical storms; and probably also earthquakes and glacial epochs. On top of that "nature" herself owes mastery on carving rhythm in creation. What else can have the utmost aesthetic appeal to human sensory than the animate (flora and fauna) and inanimate structure (mountain range, rivers, caves, gorges...) in nature !

Nature presents us the next surprise by the way of the so-called "Law of phyllotaxis". The study of phyllotaxis is so closely bound up with the History of the Spiral Theory that it is often necessary to point out that spiral phyllotaxis still exists in the vast majority of vegetative shoots, whether one accepts any Spiral Theory or not [3]. Spiral arises from a property of growth called self similarity or scaling; it is a tendency to grow in size but to maintain the same shape. For instance leaves on the stem of a flower or a branch of a tree often grow in a helical pattern, spiraling around the branch as new leaves form further out. Botanists assert that the fractions describing the plant screw axes form the stringent mathematical sequence consisting of the adjacent Fibonacci numbers ratios, that is: $1 / 2,1 / 3,2 / 5,3 / 8,5 / 13,8 / 21,13 / 34, \ldots \ldots$. Fibonacci series is the following number sequence: 1 , $1,2,3,5,8,13,21,34,55,89, \ldots \ldots \ldots$

The phyllotaxis fraction from the sequence is characteristic for different plants. For example, the fraction of $1 / 2$ is peculiar to cereals, birch, grapes; $1 / 3$ to sedge, tulip, alder; $2 / 5$ to pear, currants, plum; $3 / 8$ to cabbage, radish, flax; $5 / 13$ to spruce, jasmine etc. Practically all racemes and densely packaged botanic structures (pine and cedar cones, pineapples, cactuses, heads of sunflowers and 
many others) also strictly follow to Fibonacci numbers regularity. Pine cones are also constructed in a spiral fashion, small ones having commonly with 8 spirals one way and 13 the other. The most interesting is the pineapple - built from adjacent hexagons, three kinds of spirals appear in three dimensions. There are 8 to the right, 13 to the left and 21 vertically - a Fibonacci triple. Similarly, sunflowers have a Golden Spiral seed arrangement. This provides a biological advantage because it maximizes the number of seeds that can be packed into a seed head.

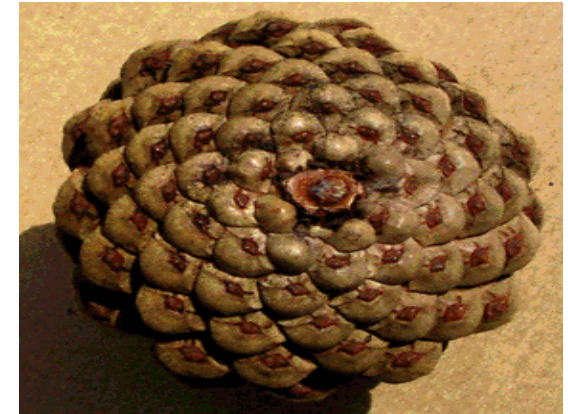

Fig. 1: Phyllotaxis structures: (a) a pine cone

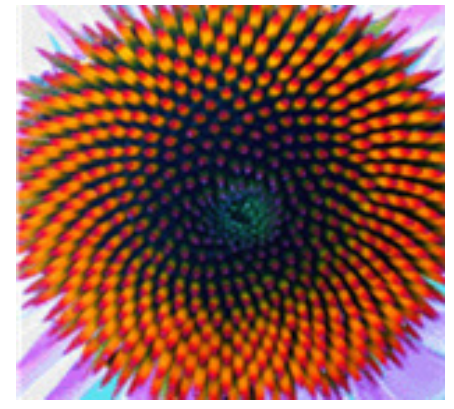

(b) a head of sunflower Source: http://www.goldenmuseum.com/

\section{Rhythm in Poetry}

The majority of oral poetry in earlier times maintains a beat. For earlier oral literature the presence of rhythm was very significant. Rhythm is the aural organization and movement of a poem's language in varieties of ways to determine and deepen its effect. The different metrical forms organized in manifold ways along with syntax and word order contribute to impression of movement and order. Every poem has a form and rhythm; it is a sequence of events or objects perceptible as a distinct pattern that is characterized by regularity, variation, grouping, and hierarchy. "Rhythm is thereby assimilated to a notion of poetry as an expression of certain truths about the world beyond it with a subtlety or forcefulness denied to nonpoetic language" [1]. The distinctiveness of poetic language possesses a special power that induces emotional response. In poetry the reoccurrences of patterns such as sound, grammatical structure, syntactic order and lexicon choice coinciding the meaning, generate the cohesion. Similarly rhythm in music implies a regular cadence or meter indexing its temporality that is tempo. After a certain amount of time has passed in a piece of music, either a change occurs or an element repeats. The constancy of this interval might seem to indicate stasis, while the unfolding of rhythm over time lends it a dynamic character.

\section{Rhythm in Architecture}

Repetition in architecture could perhaps be divided into a purely spatial, static form and a quasitemporal, dynamic form. The latter one approximates modern notions of architectural rhythm, which can be better understood by contrasting it with the former that corresponds to the older ideal of architectural harmony. Harmony as a principle of construction is typically thought to consist in the balance achieved between a building's length, width, and height. Repetition therefore assumes a more purely spatial form in architecture whenever it is used to express a relation of symmetry or equilibrium. One side matches the other, in an immediately graspable manner. Symmetry, or the use of repeated and balanced forms, is essential. Where glass appears on the one side, there must be a glass on the other, of the same dimensions and in a frame of the same shape. Repetition manifests 
itself differently in its dynamic form than in its static variant as changing time introduces a whole range of unimaginable possibilities into the field of architecture. Rhythm can be acquired through repetition, progression, radiation, gradation and contrast. Repetition is continuity or recurrence of elements including geometrical shapes, lines, forms and colors. Progression, likewise, relates a sequence or transition produced by increasing or decreasing one or more qualities; it is ordered systematic change. When elements or spaces are arranged around a centre point as in a spiral then it gives radial impression. Rhythm can be acquired through evolvement of forms and colors that is called gradation. Aesthetic values and audience's interest can be on the other hand heightened through abrupt transition or deliberate placement of elements to create oppositions. The architectural structure applying one or the other rhythmic pattern maintains a balance, that is equilibrium of the visual forces, by arranging identical elements in a single axis or by arranging dissimilar spaces by including more than one axis. Pyramid of ancient Egypt embodies progressive rhythmic pattern from top down with symmetrical balance.

The architectures evolved during human civilization irrespective of historical epoch and geographical boundaries which have applied rhythm in their structure have become timeless aesthetic entity. Aesthetic appeal becomes automatically dominant in such monuments. While regarding the major historical development of architecture one must ponder on Mediterranean basin that was Egypt. Egyptian architecture largely consists of massive burial chambers in the form of Pyramids (at Giza) and underground tombs (in the desolate Valley of the Kings, Luxor). Famous examples of Egyptian -pyramid architecture include: The Step Pyramid of Djoser (c.2630 BCE) designed by Imhotep - one of the greatest architects of the ancient world - and The Great Pyramid at Giza (c.2550 BCE), also called the Pyramid of Khufu or 'Pyramid of Cheops' - the oldest of the Seven Wonders of the World, as compiled by Antipater of Sidon (170-120 BCE). The earlier mud-brick mastabas would be built of limestone block and would be placed on top of one another, each level a little smaller than the one beneath to create a pyramid. It is the repetition of the same structure, one above the other however with little dimension than the former-that continues until the layers rise to a point of a triangle. The structure of pyramid coincides the ancient belief-man's attempt to reach closer to the realm of God. Pyramid is considered as a magnificent architecture and a timeless entity holding aesthetic essence till the date.

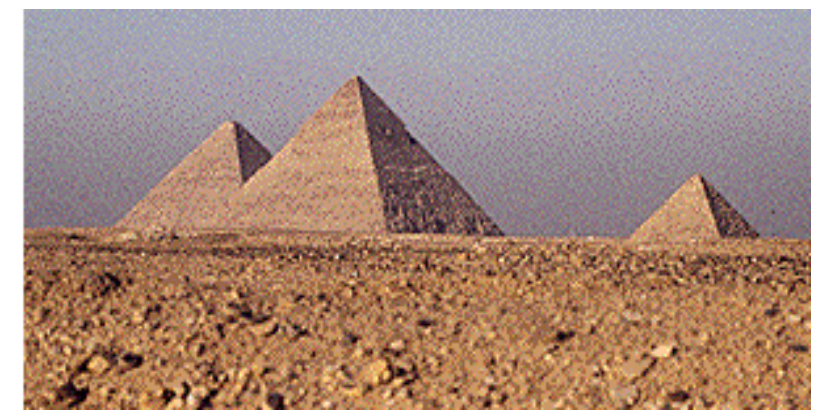

Fig. 2: Complex of pyramids in Giza http://www.goldenmuseum.com/

Similarly the Parthenon of Greek time 447 BC is a significant architectural structure that has been designed adopting regular rhythm. It is a "peripterall octastyle Doric temple" with Ionic architectural features. It stands on a platform of three steps. In common with other Greek temples, it is of post and lintel construction and is surrounded by columns carrying an entablature. There are eight columns at either end ("octastyle") and seventeen on the sides. There is a double row of columns at either 
end. The colonnade surrounds an inner masonry structure which is divided into two compartments. At either end of the building the gable is finished with a triangular pediment originally filled with sculpture. The columns are of the Doric order, with simple capitals, fluted shafts and no bases. Above the architrave of the entablature is frieze of carved pictorial panel, separated by formal architectural triglyph, typical of the Doric order. Around the cella and across the lintels of the inner columns runs a continuous sculptured frieze in low relief. This element of the architecture is Ionic in style rather than Doric [10].

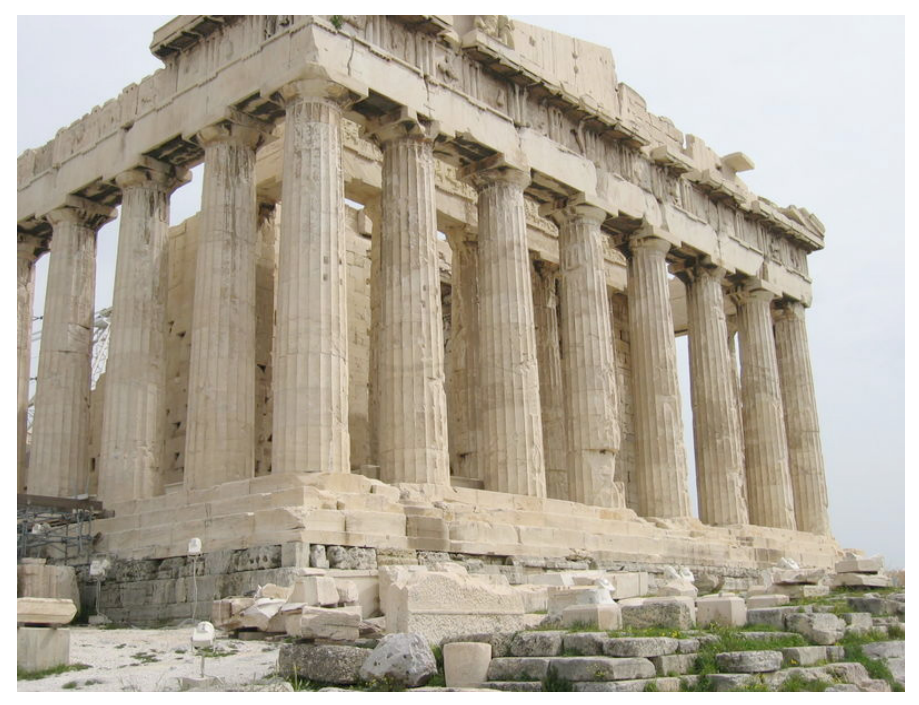

Fig. 3: The Parthenon http://www.goldenmuseum.com/

Roman architecture is characterized by the rhythm of its arches, vaulting and use of concrete. Whereas Gothic architectures embody soaring arches and huge stained glass window, ribbed vaults and flying buttresses. Not only the western architecture even the eastern monuments can be kept in the same camp. Even the popular Nepali architecture is not immune of rhythm; Hindu temples and Buddha stupas are the best examples.

\section{Nepali Architecture and Rhythm}

Ancient art was largely based on the seven great ancient civilization; Egypt, Mesopotamia, Greece, Rome, Persia, India, and China. Nepali traditional architectures such as temples, monasteries, old squares and other monuments reflect the predominance of Hindu and Buddhist religion/philosophy. Kathmandu valley, Lumbini, Janakpur and world heritage spots are the main sites enriched by Nepalese traditional architectures which can be categorized as pagoda pattern, stupa pattern and shikhar pattern. The pagoda pattern of monuments and buildings are styled with several layers roof and broad space of carved wood struts. A pagoda is a tiered tower with multiple eaves, built in traditions originating as stupa in historic South Asia and further developed in East Asia or with respect to those traditions, common to Nepal, India, China, Japan, Korea, Vietnam, Burma, Sri Lanka and other parts of Asia. The roof of this style of building is typically crowned by triangular spires surrounding in which lattice windows are used to give a look of real bell shape in outermost. The several storied pagoda style are historical remaining of Nepal as an authentic architectural design of nation almost constructed during Malla Dynasty period. The most popular sites to observe these pagoda patterns are Kathmandu's Basantapur Durbar Square area, Taleju temple 
of Basantapur, Kashthamandap and temples of around, Patan Durbar Square area, Kumbheswor temple, and many temple of around, Bhaktapur Durbar Square area, popular Nyatapola temple and Datatraya temple, others Pashupatinath and Changu Narayan temples. The temples with shallow plinths rise from some depth below ground. As for the foundation and massive plinth ( 1 to $5 \mathrm{~m}$ height) in pyramid shape, these yield even more complexity. The main peculiarities of pagoda temples with other traditional structures are their considerable wall thickness, multi-tiered roof, box type configuration, and considerable plinth width. In case of multi-tiered temples, wall thickness is not same for every storey reducing from base storey to top tower. The thickness of the walls range from $50 \mathrm{~cm}$ to $75 \mathrm{~cm}$ and are constructed with three layers in a single. Wall structure was always built with three layers, the outer face of wall is made of fired clay brick with smooth finishing and inner face is made of sun dried bricks [8]. Temple roofs have symmetrical pitches springing from the central point of the inner masonry cell. The pitches are constituted small rafters that spring from the corners in a radial arrangement [2]. The temples are one to five diminishing tier symmetric structures with brick masonry and timber elements. However most of the temples at Bhaktapur, Patan and Kathmandu have been destroyed by massive earthquake 2072.

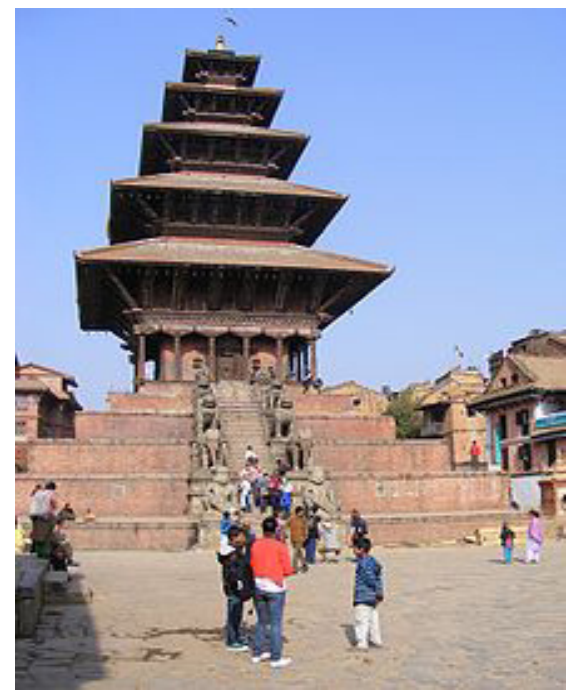

Fig. 4: Nyatapola Temple located in Bhaktapur https://en.wikipedia.org/wiki/Pagoda

The stupa Pattern of monuments and buildings are styled mainly hemispherical round shape in bottom and segmented part to part round up to top and decorated with images pattern of different sects of Buddhism atop. An architectural descendant of the burial mound, the stupa is a brick and plaster hemisphere with a pointed superstructure (seen as an image of the cosmos). Enshrining a relic of the Buddha, it serves as the sacred centre around which ritual occurs in an open-air setting[9]. The stupa is a metaphor, a sutra in itself; it embodies the meaning and essence of not just Buddhism but of the entire question of existence. Buddhist stupas and pair of big eyes in square of main body can be observed from all side easily. There are also several monasteries where monks and nuns are practically educated about Buddhism and all the monasteries inside are painted very authentic style of arts based on Buddhism philosophy. Nepal's most popular sites to see stupas are Bauddhanath, Swoyambhunath and many other stupas or Chhortens of Kathmandu valley.

The Shikhar Pattern of architectural temple is very common monuments of Hindu shrine. Shikhara, Sanskrit word translating literally to "mountain peak", refers to the rising tower in the Jain \& Hindu temple architecture of North India. Famous Krishna Mandir located at Patan Darbar 
Square and some temples at Pashupati area are some of the examples of Shikhar pattern in Nepal. The Shikhar Pattern of architectural temples consist of five to nine vertical sections forming a high pyramidal or curvilinear tower like structure and atop decorated by beautiful gajur.

The roofs of decreasing dimensions, stacked one above the other constitute the traditional style of the temples in Nepal. The Nepalese have their own terms for temples; Mandir in Nepali and Dega in Newari, do not give any hint about the style of the temple. The first impressions of the holy buildings depict uniformity but there are various conceptual differences demanding individual treatment. Earlier, many people mistakenly mentioned the temples as 'multi-storied', which in reality were merely tiered roofs, with a habitable floor below. The shrine is generally placed in the center of this floor, with the exception of few temples. The styling of the roofs may seem pretty similar to the Chinese monasteries, however it should be noted that these temples are more squarish unlike the rectangular style of the Chinese. The most significant example of this style is found in the Pashupatinath Temple in Kathmandu.

Architecture is generated by an underlying code. This order, revealed by mathematics and geometry, was first espoused by Pythagoras who lived in southern Italy, and it led to many Greek temples designed on proportional principles revealing not only supreme beauty but 'the music of the heavenly spheres' - either God or nature. Many later designers tried to capture the notion with new materials. Architecture is a variably perceived art. It is correctly experienced from several distances and speeds of movement. Like the Greek temples, they induce the feeling of finality by the absolute contrast between sunlight and blackness. The architectural melodies do not run in as strong opposition as the music. There are decorative elements that give the architecture a subtle counterpoint. High architectures are sometimes most appreciated in the holistic. So in this holistic grasp the audience takes the space in at a glance. As Grant Hilde Brand states that on the basis of evolutionary psychology the evidences suggest "pleasurable responses to certain characteristics of our surrounds are built into us in ways that transcend any immediate societal trends". He strongly argues that we cannot reject such "characteristics, their provision and obvious predilections" that underlie us all [6].

\section{Modern Architecture}

Modern architecture introduces whole range of unimaginable possibilities as it manifests differently in its dynamic form than in its static variant. Asymmetrical, imbalances, and disequilibrium may be temporarily displaced as resolution can be explored elsewhere. The Soviet constructivist and architectural theorist Moisei Ginzburg has compared the dynamism of modern design to the pulsating rhythm of industrial machinery that epitomized the new way of life being formulated in the earlier half of the twentieth century [5]. What distinguished modern architecture from everything past was the dynamic quality in its rhythm. Repetition can be mobilized at the level of city; urban sites can on the whole be configured while still making use of repetitive parts without clinging to the arrangement of a grid of rectilinear blocks or a radial agglomeration of concentric rings abiding by fixed relationship of balance and symmetry.

Modern refers to technological and engineering developments dating back to the turn of $20^{\text {th }}$ century. Modern architecture generally focuses on industrial metals such as steel, concrete and glass to enclose the vast interior space of the structure. It is based on the rational use of modern materials, the principle of functionalist planning. Usefulness and beauty are always the twin consideration in the applied architecture of modern times. Instead of viewing a building as a heavy mass of ponderous materials, the leading innovators of modern architecture consider it a volume 
of space enclosed by light, thin curtain walls and resting on slender piers. The visual aesthetic of modern architecture was largely inspired by machine and by abstract painting and sculpture. The structures are identified by clean lines minimalist interiors that allow speak for itself and take centre stage. Despite its simplistic styling that avoids extra fluff, modern architecture remains unique. In fact modern architects have created some of the most unique design to date. Modern designs are unique, warm, inviting and open creations of structural beauty. Even traditional elements added into a modern design results into the best work around the globe. New manufacturing techniques eventually led to the mass production and pre-fabrication of building construction materials, ultimately reinventing how buildings were constructed.

Modern architects seek to imbue architecture with new life and greater energy. Architects have allowed the greater experimentation, the exploration of design possibilities and more personal expression resulting in greater variation and expanded architectural range of aesthetic. Reduction and restraint are replaced by articulation and exuberance. Ornamentation is acceptable when it is abstract and integral to the building. The expressionist modern architecture focuses on creating a more vibrant, energetic architecture great visual interest.

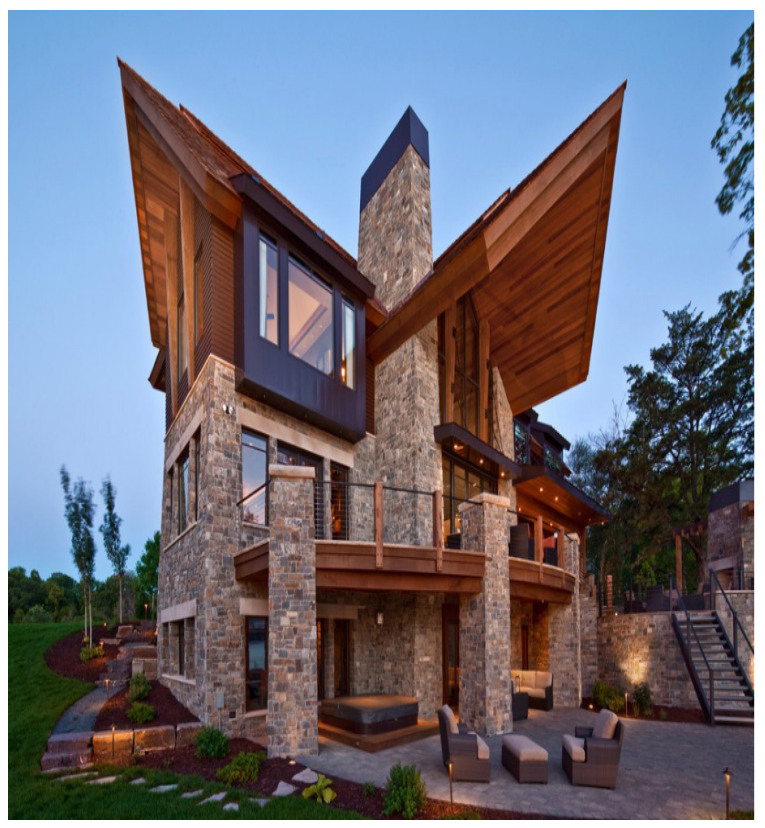

Fig. 5: http://freshome.com/2014/08/11/why-people-love-modern-architecture/

The above image of modern architecture reveals the bold, angular roof lines on both side that are so prominent in modern design - these are very unique. Everything from the vaulted ceilings, to the exposed structural elements, to the unusual linear elements - all equate to a unique, artistic design that one cannot help but be amazed by.

\section{Conclusion}

Rhythm in architecture is realized in space. Repetition is a common compositional technique in architecture whether it be in the rows of structure, a grid of opening or the stacking of materials. In columns, windows, bricks or other elements repetition helps to create a rhythm for a building, something that can be linked to natural cycles; the repeated days, our heart beat, our strides and so 
many other aspects of nature. Repetition begets order, and an important way of defining one's place in the world. Rhythm is based on five principles; they are repetition, gradation, transition, contrast and radiation. Repetition also bestows order, a chief way of defining one's place in the world. Nature herself is the best example to embed rhythm in her creation. Similarly the effect of rhythm in music, poetry, visual art is strong to move the audience with aesthetic experience. Renowned theorists of architecture have approved the connection of rhythm with aesthetics that the role of repetition is on the economy of vision. And it is the eye that tends to group together things of the same type even when elements taken in pairs are somewhat different; a structural resemblance dominates these differences.

History of architecture exhibits the search for structural systems to make exciting places for spiritual and ritual events. The ancient societies believed that structure was basic to the spiritual meaning; the Greek temples, French Gothic churches, pyramids in ancient Egypt, temples of different styles in Asia serve the perfect example. However buildings do not stand alone in our time. They are designed to fit into towns and cities containing spaces where life is lived. Rhythm is frequently desired within striking architectural compositions. Certain parts of human brain consistently light up when nervous system experiences beauty. Culture and experience play significant role to teach the sense of beauty to human psyche to some extent. However certain qualities are constantly found regardless of culture and experience. These qualities are grids, zigzag, spirals and curves. This indicates that beauty may be universal on some level. Experience of beauty is fundamental to human nature. We find beauty in different things at different times; however the joy found in architectural space and form is universal. As spatial compositions continue to evolve so too will our understanding of the meaning behind beauty.

\section{References}

[1] Attridge D (1982), The Rhythms of English Poetry, Longman Inc., New York: 306.

[2] Bonapace C and Sestini V (2003), Traditional materials and construction technologies used in the Kathmandu valley. Paragraphic for the United Nations Educational, Scientific and Cultural, 7 Place de Fontenoy, 75352 Paris 07 SP, France N. pag.

[3] Church AH (1902), Descriptive morphology, Phyllotaxis. The New Phytologist, Botanic Garden, Oxford. 1(3) : 49-55.

[4] Eldridge R (1985), Form and content: An aesthetic theory of art. British Journal of Aesthetics, 25(4) : 303-316

[5] Ginzburg M (1982), Style and Epoch, trans. Anatole Senkevitch, Cambridge, MA: MIT Press: 81.

[6] Hilder BG (1999), Origin of Architectural Pleasure, University of California Press: London.149

[7] Nietzsche F (1974), The Gay Science, Trans. W. Kaufmann. New York: Random House: 139.

[8] Thapa JB (2011), Test and simulation of brick masonry wall of historic buildings. Partial fulfillment of the requirements for the Degree of Master of Science in structural engineering. Institute of Engineering, Pulchowk campus, Tribhuvan University, Nepal N. pag.

[9] Retrieved(2017.7.15),(http://www.historyworld.net/wrldhis/PlainTextHistories.asp?historyid $=\mathrm{ab} 96$

[10] Retrieved (2017.8.5), Wikipedia, free encyclopedia. Parthenon https://en.wikipedia.org/wiki/ parthenon. 